\title{
PENTINGNYA PERAWAT DALAM MENERAPKAN PELAYANAN KESELAMATAN PASIEN DI RUMAH SAKIT
}

\author{
Ade Sulistya Lubis/181101121 \\ adesulistyalubis@gmail.com
}

\begin{abstract}
ABSTRAK
Latar belakang: Keselamatan pasien rumah sakit adalah suatu sistem yang diterapkan untuk mencegah terjadinya cedera akibat perawatan medis dan kesalahan pengobatan Tujuan: Tujuan pembandigan dari beberapa jurnal dan sumber lainnya agar dapat mengetahui pentingnya perawat dalam menerapkan pelayanan. Metode: Jurnal ini menggunakan metode tersearch dan analisis dari berbagai sumber seperti buku teks, buku referensi jurnal, e-book, dan juga membandingkan beberapa jurnal yang berhubungan dengan perawat menerapkan pelayanan keselamatan pasien di rumah sakit. Hasil: Perawat harus memiliki kesadaran akan adanya potensi bahaya yang terdapat di lingkungan pasien melalui pengidentifikasian bahaya yang mungkin terjadi selama berinteraksi dengan pasien selama 24 jam penuh, karena keselamatan pasien dan pencegahan terjadinya cedera merupakan salah satu tanggung jawab perawat selama pemberian asuhan keperawatan berlangsung. Kesimpulan: Untuk mencegah terjadinya cidera pada pasien, perawat dituntut memiliki pengetahuan dan ketrampilan yang memadai tentang eselamatan pasien.
\end{abstract}

Kata kunci: Perawat, Pelayanan, Keselamatan pasien.

Background: Hospital patient safety is a system that is implemented to prevent injury from medical care and medication errors. Objective: The purpose of comparing several journals and other sources in order to know the importance of nurses in implementing services. Methods: This journal uses the search method and analysis from various sources such as textbooks, journal reference books, e-books, and also compares several journals related to nurses implementing patient safety services in hospitals. Results: Nurses must have awareness of the potential hazards in the patient's environment through the identification of hazards that may occur during interaction with patients for 24 hours straight, because patient safety and prevention of injury is one of the nurses' responsibilities during the provision of nursing care takes place. Conclusion: To prevent injury to patients, nurses are required to have adequate knowledge and skills about patient safety.

Key words: Nurse, service, patient safety 


\section{LATAR BELAKANG}

\section{PENDAHULUAN}

Keselamatan pasien rumah sakit adalah suatu sistem yang diterapkan untuk mencegah terjadinya cedera akibat perawatan medis dan kesalahan pengobatan melalui suatu sistem assesment resiko, identifikasi dan pengelolaan faktor risiko, pelaporan dan analisis insiden, kemampuan belajar dan tindak lanjut dari insident serta implementasi solusi untuk meminimalkan timbulnya risiko (Dep Kes RI, 2006).

Taylor, et al. (1993) mengungkapkan bahwa keperawatan merupakan profesi yang berfokus kepada pelayanan dan bertujuan membantu pasien mencapai kesehatannya secara optimal. Oleh karena itu pada saat memberikan asuhan keperawatan kepada pasien, perawat harus mampu memastikan bahwa pelayanan keperawatan yang diberikan mengedepankan keselamatan. Perawat harus memiliki kesadaran akan adanya potensi bahaya yang terdapat di lingkungan pasien melalui pengidentifikasian bahaya yang mungkin terjadi selama berinteraksi dengan pasien selama 24 jam penuh, karena keselamatan pasien dan pencegahan terjadinya cedera merupakan salah satu tanggung jawab perawat selama pemberian asuhan keperawatan berlangsung.

Perawat mempunyai peranan penting dalam menentukan baik buruknya mutu pelayanan kesehatan di rumah sakit karena perawat merupakan tenaga terbanyak dan mempunyai waktu kontak dengan pasien lebih lama dibandingkan tenaga kesehatan yang lain. Pelayanan kesehatan pada dasarnya untuk menyelamatkan pasien, namun dengan berkembangnya ilmu teknologi pelayanan kesehatan menjadi semakin kompleks dan berpotensi terjadi kecelakaan pasien apabila tidak dilakukan dengan hati-hati (Depkes RI, 2006).

Pelaksanaan prosedur atau proses dalam pemberian pelayanan pasien yang aman di rumah sakit dapat di pengaruhi oleh pengetahuan perawat dan penerapan dari perawat pelaksana yang mengutamakan kepentingan dan keselamatan pasien. Dalam upaya membangun keselamatan pasien memerlukan komitmen yang di pengaruhi oleh pengetahuan perawat. Perawat yang memiliki pengetahuan yang baik akan keselamatan pasien pastinya 
memiliki sikap yang baik dalam meningkatkan mutu pelayanan kesehatan dan pengetahuan merupakan pangkal dari sikap, sedangkan sikap akan mengarah pada tindakan seseorang. Ketidaktahuan atau kurangnya pengetahuan perawat bisa menyebabkan cedera kecacatan pada pasien dan tidak menutup kemungkinan bisa terjadi kematian. Selama ini pelaksanaan gawat darurat dilaksanakan hanya kegiatan rutinitas saja tidak ada suatu target untuk meningkatkan pelayanan kesehatan bagi pasien. Tidak ada evaluasi yang dilakukan sehingga petugas tidak mengetahui apakah pelayanan yang diberikan telah memenuhi kebutuhan pasien atau belum, dan juga tidak mengetahui apakah pelayanan yang diberikan telah memenuhi standar akreditasi atau belum (Depkes RI, 2006).

\section{TUJUAN}

Tujuan pembandigan dari beberapa jurnal dan sumber lainnya agar dapat mengetahui pentingnya perawat dalam menerapkan pelayanan keselamatan pasien di rumah sakit.

\section{METODE}

Jurnal ini menggunakan metode tersearch dan analisis dari berbagai sumber seperti buku teks, buku referensi jurnal, e-book, dan juga membandingkan beberapa jurnal yang berhubungan dengan perawat menerapkan pelayanan keselamatan pasien di rumah sakit. Dari analisi berbagai sumber digunakan Untuk mengetahui bagai mana perawat dalam menerapkan pelayanan keselamatan pasien dirumah sakit. Penulisan jurnal ini dimulai pada tanggal 01 oktober 2019. Pengolahan jurnal dilakukan dengan metode membandingkan beberapa jurnal yang berhubungan dengan pentingnya perawat dalam menerapkan pelayanan keselamatan pasien di rumah sakit.

\section{HASIL}

Dari jurnal (Dewi,Mursidah.(2012). Pengaruh Pelatihan Timbang Terima Pasien Terhadap Penerapan Keselamatan Pasien Oleh Perawat Pelaksana Di RSUD Raden Mattaher Jambi.Jurnal Health \& Suport.5,(3):647:652). Mengemukakan 
Untuk mencegah terjadinya cidera pada pasien, perawat dituntut memiliki pengetahuan dan ketrampilan yang memadai tentang eselamatan pasien. Perawat harus mengetahui (1) ketepatan identifikasi pasien (2) mengetahui komunikasi yang efektif (3) peningkatan kewaspadaan terhadap obat-obat yang perlu diwaspadai (4) mengetahui tepat lokasi, tepat prosedur, tepat pasien operasi (5) pencegahan infeksi akibat tindakan (6) dan pengetahuan tentang pasien resiko jatuh. Dengan adanya pelatihan atau seminar mengenai pengetahuan keselamatan pasien di harapkan mampu meningkatkan pengetahuan perawat, sehingga perawat mampu melaksanakan asuahan keperawatan dengan baik pula dan kecelakaan pasien dapat di cegah sedini mungkin (Depkes, 2006).

\section{PEMBAHASAN}

Keselamatan pasien merupakan suatu sistem untuk mencegah terjadinya cedera yang disebabkan oleh kesalahan akibat melaksanakan suatu tindakan atau tidak mengambil tindakan yang seharusnya diambil (TKPRS RSUP Sanglah Denpasar, 2011).

Tujuan penerapan sistem keselamatan pasien di rumah sakit antara lain:

1. Terciptanya budaya keselamatan pasien dirumah sakit

2. Meningkatnya akuntabilitas rumah sakit terhadap pasien dan masyarakat.

3. Menurunnya Kejadian Tak Diharapkan (KTD)

4. Terlaksananya program pencegahan sehingga tidak terjadi pengulangan KTD

Dalam upaya pencapaian tujuan keselamatan pasien ini, setiap rumah sakit wajib melaksanakan sistem keselamatan pasien melalui upaya- upaya sebagai berikut:

1. Akselerasi program infeksion control prevention (ICP)

2. Penerapan standar keselamatan pasien dan pelaksanaan 7 langkah menuju keselamatan pasien rumah sakit. Dan di evaluasi melalui akreditasi rumah sakit

3. Peningkatan keselamatan penggunaan darah (blood safety). 
4. Dievaluasi melalui akreditasi rumah sakit.

5. Peningkatan keselamatan pasien di kamar operasi cegah terjadinya wrong person, wrong site, wrong prosedure (Draft SPM RS:100\% tidak terjadi kesalahan orang, tempat, dan prosedur di kamar operasi)

6. Peningkatan keselamatan pasien dari kesalahan obat. 7. Pelaksanaan pelaporan insiden di rumah sakit dan ke komite keselamatan rumah sakit.

\section{KESIMPULAN}

Keselamatan pasien rumah sakit adalah suatu sistem yang diterapkan untuk mencegah terjadinya cedera akibat perawatan medis dan kesalahan pengobatan melalui suatu sistem assesment resiko, identifikasi dan pengelolaan faktor risiko, pelaporan dan analisis insiden, kemampuan belajar dan tindak lanjut dari insident serta implementasi solusi untuk meminimalkan timbulnya risiko. keperawatan merupakan profesi yang berfokus kepada pelayanan dan bertujuan membantu pasien mencapai kesehatannya secara optimal. Oleh karena itu pada saat memberikan asuhan keperawatan kepada pasien, perawat harus mampu memastikan bahwa pelayanan keperawatan yang diberikan mengedepankan keselamatan.

\section{SARAN}

keselamatan pasien merupakan prioritas utama untuk dilaksanakan di rumah sakit dan hal itu terkait dengan isu mutu dan citra rumah sakit. Oleh karena itu pelaksanaan sistem manajemen mutu dengan meningkatkan keselamatan pasien "patient safety" (Jaiswal, 2016), yang diharapkan dapat menurunkan angka kematian akibat cedera medis dapat dicegah dengan membangun dan membudayakan keselamatan pasien di rumah sakit (Bea, Pasinringi, \& Noo, 2013). 


\section{REFERENSI}

Cahyono, S.B.(2008). Membangun

Budaya Keselamatan Pasien

Dalam Praktik Kedokteran.

Yogyakarta: Kanisius

Dewi,Mursidah.(2012). Pengaruh

Pelatihan Timbang Terima

Pasien Terhadap Penerapan

Keselamatan Pasien Oleh

Perawat Pelaksana Di RSUD

Raden Mattaher Jambi.Jurnal

Health \& Suport.5,(3):647:652.

Firawati.,Pabuty,A.,Putra,A.S.(2012).Pel

aksanaan Program Keselamatan

Pasien Di RSUD Solok: Jurnal

kesehatan masyarakat.6,(2):7378.

Keles, A. W., \& Ch, G. D. K. (2012). Analisis Pelaksanaan Standar

Sasaran Keselamatan Pasien

Di Unit Gawat Darurat RSUD

Dr. Sam Ratulangi Tondano

Sesuai Dengan Akreditasi

Rumah Sakit Versi 2012

Implementation Analysis of

Standards Patient Safety

Goals In Emergency

Department $\quad D r \quad$. Sam
Ratulangi Tondano Hospital Accordance With Version 2012 Hospital Accreditation, 250-259.

KEMENKES RI. (2010). Peraturan

Menteri Kesehatan RI No 1087 Tentang Standar Kesehatan dan Keselamatan Kerja di Rumah Sakit.

Kemenkes RI. 2011. Peraturan Menteri Kesehatan Republik Indonesia Nomor1691/MENKES/PER/VI II/2011 tentang Keselamatan Pasien Rumah Sakit. Jakarta: Depkes RI.

Kemenkes RI. 2006. Panduan Nasional Keselamatan Pasien Rumah Sakit (Patient Safety): Utamakan Keselamatan Pasien. Jakarta: Depkes RI.

Kemenkes RI. 2008. Panduan Nasional Keselamatan Pasien Rumah Sakit (Patient Safety): Utamakan Keselamatan Pasien. Jakarta: Depkes RI 
Nugroho,SriH.P.,Sujianto,U (2014).

Supervisi Kepala Ruang Model

Proctor Untuk Meningkatkan

Pelaksanaan Keselamatan

Pasien. Jurnal Keperawatan

Indonesia.20, (1):56-64

Nursalam. (2015). Metodelogi Penelitian

Ilmu Keperawatan Pendekatan

Praktisi Edisi 3. Jakarta:

Salemba Medika

R.H.Simamora (2019). Buku ajar pelaksanaaan indentifikasi

pasien. Uwais Inspirasi indonesi

R.H. Simamora. (2019). The infiuence of Training handover based SBAR

Communication for Improving patients safety. Indian journal of public heath research \& Deveopment

R.h. Simamora (2019). Documentation of Patient Identifikasi Into the hectronic system to improve the quality of nursing serviceec International) journal of soenrifio \& technology tesearch.

Simamora, R. H. " Buku Aajar keselamatan pasien melalui timbang terima pasien berbasis komunikasi

efektif:

SBAR.."(2018).

Setiyani, M. D. (2016). Implementasi Sasaran Keselamatan Pasien Di Ruang Rawat Inap RSU Kabupaten Tangerang. JKFT, (2), 59-69

Tri Herawat, Yennike(2015). Budaya Keselamatan Pasien Di Ruang Rawat Inap Rumah Sakit $\mathrm{X}$ Kabupaten Jember, Jurnal IKESMA Volume 11 Nomor 1 Maret.

Potter \& Perry, (2005). Buku Ajar Fundamental Keperawatan : Konsep, Proses, dan Praktik. Edisi 4. Jakarta : EGC.

Potter, P. A., \& Perry, A. G., (2010). Fundamental of nursing. Buku 1, edisi 7. Jakarta : Salemba Medika. 